ФИЛОНЕНКО Виктор Иванович - доктор социологических наук, профессор; директор Центра социально-политических исследований Института философии и социально-политических наук Южного федерального университета (344065, Россия, г. Ростов-на-Дону, пер. Днепровский, 116, ipsps@sfedu.ru; vfilonenko@sfedu.ru)

ШТОМПЕЛЬ Людмила Александровна - доктор философских наук, профессор кафедры теории культуры, этики и эстетики Института философии и социально-политических наук Южного федерального университета (344065, Россия, г. Ростов-на-Дону, пер. Днепровский, 116; lashtompel@ gmail.com)

ШТОМПЕЛЬ Олег Михайлович - доктор философских наук, профессор кафедры теории культуры, этики и эстетики Института философии и социально-политических наук Южного федерального университета (344065, Россия, г. Ростов-на-Дону, пер. Днепровский, 116; omshtompel@sfedu.ru)

\title{
СОЦИАЛЬНАЯ ЗАГРЯЗНЕННОСТЬ ГОРОДСКОЙ СРЕДЫ КАК ФАКТОР ЕЕ ДЕГРАДАЦИИ
}

\begin{abstract}
Аннотация. В статье представлены результаты социологического исследования городов Южного федерального округа, проведенного с целью определения степени социальной загрязненности аудиовизуальной городской среды. Проведенный сравнительный анализ оценок горожанами отдельных элементов городской среды позволил выявить наличие широкого диапазона социального загрязнения аудиовизуальной среды городов Южного федерального округа - от оскорбительных надписей до ненормативной лексики. Зафиксированы снижение ценности грамотной литературной речи и высокий уровень шума.

Ключевые слова: социальная загрязненность, город, городская среда, аудиовизуальная среда, визуальный, аудиальный, горожанин
\end{abstract}

$\mathrm{O}^{\prime}$ беспечение высокого качества жизни людей - это приоритетная задача, решение которой оценивается по многим параметрам. Одним из них выступает степень социального загрязнения. Тема социального загрязнения проблематизировалась в контексте изучения деструктивных методов управления человеческими ресурсами, приводящих к стрессогенным последствиям для работников, в т.ч. к снижению уровня адаптации организма, увеличению частоты случаев соматических и инфекционных заболеваний, снижению работоспособности, увеличению профессиональной заболеваемости [Федорова, Парсюкевич 2013]. Американский исследователь Джеффри Пфеффер оценивает негативные последствия феномена социального загрязнения (social pollution) как не менее значительные, чем загрязнение окружающей природной среды [Pfeffer 2010]. Однако социальная загрязненность имеет более широкий масштаб. Мы рассматриваем ее как множественность следов присутствия человека (его деятельности и поведения) в среде его обитания, не согласующихся с культурными нормами и установлениями и тем самым влияющих отрицательным образом на социальное самочувствие населения.

Среда обитания человека высокоурбанизированного общества ( Россия относится к числу высокоурбанизированных стран) - это, прежде всего, городская среда. Городская среда рукотворна: она включает в себя здания, сооружения, комплексы застройки, составляющие «тело» современого города, а также системы коммуникаций (дороги, линии электропередач и т.п.), рекреационные зоны (парки, скверы, набережные и т.д.). Внутри этих вещественно-предметных элементов разворачивается жизненная активность - деятельность, общение, поведение людей. Эта «жизненная активность» - система социальных микро- и макровзаимодействий, практик повседневной жизни образует «соци- 
альную ткань» города, без которой этот вид поселения не существует. Таким образом, городская среда включает в себя как физическую, так и собственно социально-культурную среду. Разнообразные воздействия на городскую среду - от вырезанного на коре дерева мема «Здесь был Вася» до оскорбительных или проковационных надписей на заборах и бранной речи - порождают у человека чувства беспокойства, беззащитности, уныния, одиночества, неприкаянности, униженности, ощущения заброшенности, опасности, бессилия. Эти «следы» воздействия на городскую среду обрисовывают диапазон возможного социального загрязнения городской среды, воспринимаемой как визуально, так и аудиально.

Привнесение в городскую среду элементов, чуждых данной культуре или осуждаемых, приводит к рассогласованию социального и культурного, о котором писал Р. Мертон [Мертон 1966], и к разрывам в ткани социального, на которые указывал Ж. Бодрийяр [Бодрийяр 2000]. Действительно, любое (сознательное или бессознательное) воздействие индивида на среду своего обитания (естественную или искусственную) влечет за собой разные (как позитивные, так и негативные) последствия как для сложно дифференцированного общества в целом, так и для его отдельных сегментов. Такого рода воздействия, указывал Р. Мертон, должны быть предметом эмпирического исследования, а не априорного постулирования.

Источниками социального загрязнения выступают, во-первых, представители других культур, для которых предлагаемый ими тип поведения является органичным, естественным, привычным (в их культуре так принято: здесь «работают» различия в ценностно-нормативной сфере, а также в привычках, воспитании, престиже, обычаях, моде). В качестве примера можно привести демонстративную эротичность или, напротив, закрытость одеждами. Во-вторых, загрязнителями могут быть субъекты, находящиеся в маргинальном состоянии. Дозволенность ранее недозволенного, опривычивание (хабитуализация) недопустимого через «загрязнение» социального (в данном случае - городской среды) трансформирует «культурное». Социальное загрязнение происходит и тогда, когда отдельные фрагменты городской среды как бы являются «ничейными», они разрушаются, руинизируются, становятся объектами вандализма. Но в любом случае социальная загрязненность оценивается в ходе персонального опыта взаимодействия человека со средой в единстве ее физического и социального аспектов.

А.В. Микляева и П.В. Румянцева показывают, что оценить персональный опыт взаимодействия человека со средой возможно на основе шкалы «Восприятие городской среды», которая предлагается M.L. Felonneau [Микляева, Румянцева 2011]. Испытуемым предлагалось оценить место своего проживания по следующим параметрам: наличие разбитых окон, расклеенных объявлений; людей, справляющих нужду в общественных местах, наличие разрушенных и полуразрушенных домов, выброшенного на улицу хлама, заброшенных автомобилей, мусора на тротуаре, вандализма, собачьих экскрементов, заброшенных строений, толкающихся людей людей, плюющих на землю, шаек молодых людей, разгуливающих вокруг, высокого уровня шума днем, людей, мешающих передвигаться, граффити, конфликтов на улице, шума ночью, распространенность продажи наркотиков на улице, наличие групп людей, нарушающих закон, заброшенных территорий, пустырей, провоцирующего поведения, людей, мусорящих на улице [Felonneau 2004].

Какова степень социального загрязнения городов ЮФО? Для ответа на этот вопрос обратимся к результатам анкетного опроса горожан Южного федерального округа, осуществленного авторами в 2018 г. при поддержке гранта РФФИ 
(проект № 18-011-00841)1․ Анализ ответов респондентов обнажил дисбаланс между различными субъектами ЮФО и городами внутри самих этих субъектов относительно оценки развитости аудиовизуальной среды городов и восприятия ее жителями. Так, например, в ответе на вопрос: «Нравится ли Вам ваш город?» - горожане из Ростовской, Волгоградской и Астраханской обл. явно отстают от горожан Краснодарского края, Калмыкии, Адыгеи и Крыма. На этот вопрос отвечают положительно 78,0\% респондентов из Ростовской обл., 74,5\% - из Волгоградской, 77,5\% - из Астраханской, в то время как нравится их город 95,0\% жителей Краснодарского края, 92,0\% - Калмыкии, 89,8\% - Адыгеи и 87,3\% опрошенных из Крыма.

При этом возникает существенный разрыв между ответом на этот вопрос и ответом на вопрос: «Считаете ли Вы, что ваш город уютный и привлекательный?» Положительно отвечают на этот вопрос только $65,6 \%$ респондентов из Ростовской обл., 57,7\% - из Волгоградской, 60,6\% - из Астраханской, в то же время уютным и привлекательным свой город считают $89,4 \%$ респондентов из Краснодарского края, 86,7\% из Адыгеи, 79,8\% из Крыма, 72,0\% из Калмыкии. Это может означать, что ценность города в первую очередь определяется не его эстетическим уровнем и уютом, а другими факторами (например, возможностями, которые он предоставляет для работы или для отдыха, или человеческими связями, которые он олицетворяет).

Примечательно, что и внутри самих регионов складывается противоречивая картина: если в самой столице Ростовской обл. $83,2 \%$ респондентов утверждают, что им нравится их город и при этом $72,6 \%$ считают, что он уютный и привлекательный, то, например, в Гуково доля жителей, отвечавших положительно на первый вопрос составляет уже 40,0\%, а на второй вопрос - только 5,0\%. Данное противоречие в первую очередь связано с тем, что именно в депрессивных городах люди настроены более пессимистически, а аудиовизуальную среду города оценивают в значительной степени отрицательным образом. Так, среди городов юга России в ответе на вопрос: «Представьте, что Вы мэр города и у Вас есть бюджет в 1 млрд рублей, которые Вы можете распределить между несколькими статьями. Выберите наиболее важные из них (но не более трех)», - респонденты из Гуково лидируют в выборе следующих вариантов: «сделать город более чистым, взять на работу больше дворников, закупить новые подметально-уборочные машины» - 70\%. Интересно, что с ними солидарны жители Таганрога $(71,7 \%)$, тогда как в Ростове таковых набралось 46,7\%. В Краснодарском же крае такого разрыва у некоторых городов нет: в самом Краснодаре вариант ответа «сделать город более чистым, взять на работу больше дворников» выбрали 18,3\% опрошенных, в Новокубанске $-13,3 \%$, в Абинске $-17,2 \%$ опрошенных (в Горячем Ключе - 36,7\% респондентов).

Оценка уровня привлекательности городской среды во многом зависит от архитектурно-планировочного решения, в соответствии с которым создавался город. Так исторически сложилось, что шахтерские города Гуково и Новошахтинск строились мозаичным образом: в виде поселков вокруг шахт. В результате целостный образ города не складывается, возникают проблемы с транспортом, с медицинским и социальным обслуживанием. Угольная промышленность в Ростовской обл. постепенно сворачивалась, в результате чего

\footnotetext{
1 Выборка исследования многоступенчатая: выделены 8 субъектов Южного федерального округа (Адыгея, Калмыкия, Краснодарский край, Астраханская, Волгоградская, Ростовская обл., Республика Крым и город федерального значения Севастополь); выбраны 5 типов городов (крупнейший, крупный, большой, средний, малый), внутри каждого типа сами города определялись случайным образом (путем жеребьевки). Общий объем выборочной совокупности составил 1532 чел. В результате реализации полевого этапа после выбраковки некачественно заполненных анкет число опрошенных составило 1371 чел.
} 
возникли проблемы экономического и социального характера. В подтверждение тезиса о важности архитектурно-планировочных решений для города и представления о привлекательности своего города можно привести следующие факты: $84,2 \%$ респондентов из Гуково и $79,2 \%$ из Новошахтинска считают, что архитектурно-планировочное решение их городов является неудачным, в то время как в Азове доля жителей, отвечающих на данный вопрос отрицательно, только $18,2 \%$, в Севастополе - 20,6\%.

В Азове $91,2 \%$ респондентов считают, что их город является уютным и привлекательным, в отличие от $5,0 \%$ таковых в Гуково. Отметим, что в ответе на вопрос: «Есть ли в Вашем городе здания, отражающие национальный или региональный колорит?» - лидируют с положительным откликом, как и следовало ожидать, жители Адыгеи - 83,2\%, жители Калмыкии - 96,0\% и Крыма - 84,8\% опрошенных. Менее всего наличие такого рода зданий отмечено в малых моногородах, находящихся в кризисных ситуациях: в Нариманове (Астраханская обл.) $-21,4 \%$, Гуково (Ростовская обл.) - 20,0\%, Новошахтинске (Ростовская обл.) $-29,2 \%$.

В нашем исследовании физические и социальные аспекты городской среды были детализированы, а степень «социальной загрязненности» среды оценивалась по ответам на несколько вопросов: «Используют ли в Вашем присутствии прохожие ненормативную лексику?»; «Оскорбляет ли Вас ненормативная лексика?»; «Есть ли на заборах (на стенах домов, гаражей) вашего города рисунки или надписи следующего характера: бессмысленные, пропагандистские, историко-культурные, социально-конструктивные, социально-деструктивные, оскорбительные, другие (напишите)»; «Случаются ли в вашем городе открытые столкновения (ссоры, драки) на этнической почве?»; «Считаете ли Вы своей город шумным?»; «Считаете ли Вы своей город чистым?»; «Принято ли в вашем городе выражать свою эротичность в поведении или в одежде?»; «Какие визуальные объекты кажутся Вам наиболее непривлекательными в Вашем городе?»

Как раз последний вопрос относится к типу открытых вопросов, и на него мы получили множество разнообразных ответов. Помимо непривлекательных, с их точки зрения, конкретных улиц, районов и объектов своих городов, респонденты отметили: «состояние дорог и жилых кварталов», «старые дома», «аварийные здания», «архитектуру», «архитектуру XX века», «баннеры, рекламные щиты», «неаккуратные заброшенные заборы», «нагромождения магазинов на центральных улицах», «мусорные свалки», «мусорные баки», «мусорки во дворах», «мусор», «много рекламы», «мемориальные доски», «машины во дворах», «ларьки на набережной», «здания, которые опасны для жизни людей», «здания в спальных районах», «застройки парков “коробками”», «запущенные фонтаны», «заброшенные здания», «заброшенные заводы», «дома под снос», «дома олигархов», «дешевая коммерческая недвижимость», «дворы вдали от центра», «грязные улицы», «грязь», «высотки в историческом центре», «брошенные стройки», «брошенные шахты», «бедные районы», «шум машин», «ямы на дорогах».

О степени социальной загрязненности можно судить по фактам умышленного унижения чести и достоинства личности, выраженного в неприличной форме, т.е. оскорблении. В связи с этим в анкете был предусмотрен вопрос: «Есть ли на заборах (на стенах домов, гаражей) вашего города рисунки или надписи оскорбительного характера?» 49,0\% подростков и 50,5\% молодежи до 30 лет положительно ответили на этот вопрос. Если прибавить к этому то, что 12,4\% подростков и $16,9 \%$ молодежи до 30 лет подтвердили наличие в визуальном пространстве города социально-деструктивных надписей, а 78,6\% и 77,0\% респондентов этих же возрастных групп отметили наличие бессмысленных надписей, то ста- 
новится очевидным, что в городской среде содержатся элементы, снижающие самочувствие молодежи и дезориентирующие ее (см. табл. 1).

Таблииа 1

Распределение ответов на вопрос: «Есть ли на заборах (на стенах домов, гаражей) вашего города рисунки или надписи следующего характера?», \%

\begin{tabular}{|l|c|c|c|c|c|}
\hline & $\begin{array}{c}\text { До 17 лет } \\
\text { включительно }\end{array}$ & $\mathbf{1 8 - 3 0}$ лет & $\mathbf{3 1 - 4 4}$ года & $\mathbf{4 5 - 5 9}$ лет & $\begin{array}{c}\text { 60 лет } \\
\text { и старше }\end{array}$ \\
\hline Бессмысленные & 78,6 & 77,0 & 70,0 & 63,0 & 69,0 \\
\hline Пропагандистские & 16,6 & 31,8 & 20,5 & 25,0 & 24,8 \\
\hline Историко-культурные & 14,5 & 23,2 & 16,5 & 11,4 & 16,3 \\
\hline $\begin{array}{l}\text { Социально- } \\
\text { конструктивные }\end{array}$ & 11,0 & 15,2 & 7,3 & 8,2 & 9,3 \\
\hline $\begin{array}{l}\text { Социально- } \\
\text { деструктивные }\end{array}$ & 12,4 & 16,9 & 13,9 & 13,0 & 10,9 \\
\hline Оскорбительные & 49,0 & 50,5 & 43,2 & 39,7 & 35,7 \\
\hline Другие & 3,4 & 6,5 & 10,6 & 11,4 & 12,4 \\
\hline
\end{tabular}

Везде в визуальной среде городов во всех регионах респонденты отмечают наличие на стенах домов, гаражей, заборов рисунки и надписи различного содержания - от пропагандистских до социально-деструктивных. Однако лидируют надписи бессмысленного характера: отметили этот факт 82,3\% респондентов в Крыму, 80,0\% - в Калмыкии, 74,6\% - в Ростовской обл., 62,0\% - в Краснодарском крае, 79,5\% - в Волгоградской обл., 74\% - в Астраханской обл. Меньше всего их наличие зафиксировали респонденты в Адыгее $-55,0 \%$, но и здесь они стоят на 1-м месте. Заметили респонденты много надписей и рисунков оскорбительного характера, и здесь горожане различных областей отвечают по-разному; однако везде, кроме Калмыкии (где их, по мнению респондентов, нет), оскорбительные надписи стоят на 2-м месте: их наличие фиксируют 48,1\% опрошенных в Ростовской обл., 28,9\% - в Краснодарском крае, 59,6\% - в Крыму, 56,8\% - в Волгоградской обл., 57,5\% - в Астраханской обл. В Адыгее их отметили $29,4 \%$ респондентов, но они все равно находятся на 2-й позиции.

Надписи историко-культурного характера занимают 3-е место по распространению, по мнению опрошенных, в Краснодарском крае и в Адыгее. Вероятно, в реализации культурной политики этих двух субъектов Южного федерального округа придается большое значение этому элементу визуальной городской среды, что приносит свои положительные плоды. В других же субъектах ЮФО респондентами на 3-м месте отмечены пропагандистские надписи.

Наряду с визуально воспринимаемой информацией, городская среда характеризуется и разнообразными звуками. В шкале, предложенной M.L. Felonneau, из аудиального модуса городской среды отмечены только «высокий уровень шума днем» и «шум ночью». Мы задали респондентам вопрос: «Считаете ли Вы своей город шумным?» 37,2\% подростков и 48,4\% молодых людей до 30 лет ответили на этот вопрос положительно, тогда как среди других возрастных категорий положительно ответили на этот вопрос немного меньшее число респондентов (от $28,9 \%$ до $34 \%$ ).

Аудиальная составляющая городской среды весьма разнообразна. Нам было важно оценить, каким образом представлена в разных типах городов основа российской культуры - грамотная литературная речь. Несмотря на наличие 
большего числа культурных учреждений, вузов, жителей с высоким уровнем образования, основа российской культуры - литературная речь - в крупнейших городах встречается реже, чем в крупных и в малых. Лишь 20,5\% респондентов из крупнейших городов отметили ее наличие, тогда как ненормативной лексики $-62,3 \%$, жаргонизмов $-46,7 \%$, лая собак $-38,0 \%$, пения птиц $-21,7 \%$. 5-е место по слышимости грамотная литературная речь занимает в крупных и малых городах, 6-е - в больших и средних (см. табл. 2). Большой процент ненормативной лексики (во всех типах городов) подтверждает, что анонимный характер контактов в городах при разобщенности городских сообществ снижает уровень социального контроля и, соответственно, самоконтроля. Важно отметить, что ненормативная лексика лидирует во всех типах городов, за исключением малых, но здесь она уступает место лишь природным звукам (пению птиц). Следовательно, источник ее широкого распространения не связан с типом города.

Таблица 2

Распределение ответов на вопрос: «Часто ли в Вашем городе слышны...» (по типам городов), \%

\begin{tabular}{|l|c|c|c|c|c|}
\hline & $\begin{array}{c}\text { Крупнейшие города } \\
\text { (более 1 млн жителей) }\end{array}$ & $\begin{array}{c}\text { Крупные } \\
\text { города }\end{array}$ & $\begin{array}{c}\text { Большие } \\
\text { города }\end{array}$ & $\begin{array}{c}\text { Средние } \\
\text { города }\end{array}$ & $\begin{array}{c}\text { Малые } \\
\text { города }\end{array}$ \\
\hline $\begin{array}{l}\text { Грамотная } \\
\text { литературная речь }\end{array}$ & 20,5 & 28,4 & 15,1 & 14,3 & 20,8 \\
\hline $\begin{array}{l}\text { Ненормативная } \\
\text { лексика }\end{array}$ & 62,3 & 47,5 & 42,6 & 63,0 & 37,1 \\
\hline Жаргонизмы & 46,7 & 37,5 & 21,7 & 31,2 & 21,6 \\
\hline Пение птиц & 21,7 & 36,0 & 41,5 & 29,2 & 38,6 \\
\hline Лай собак & 38,0 & 29,9 & 33,5 & 30,5 & 35,5 \\
\hline Звон колоколов & 13,2 & 17,6 & 22,4 & 18,8 & 15,4 \\
\hline Другое & 6,1 & 10,0 & 8,1 & 7,8 & 7,3 \\
\hline
\end{tabular}

Проследить засорение аудиальной городской среды ненормативной лексикой можно и в проекции разных субъектов ЮФО. Ее наличие отметили 60,9\% опрошенных жителей городов Ростовской обл., 65,4\% - Волгоградской обл., 69,9\% опрошенных из Астраханской обл. Контрольный вопрос: «Используют ли в Вашем присутствии прохожие ненормативную лексику?» - показал, что аудиальная среда городов засорена ненормативной лексикой еще больше: $88,5 \%$ респондентов из Ростовской обл., 90,1\% из Волгоградской обл., 93,2\% опрошенных из Астраханской обл. и больше чем половина опрошенных из других областей (за исключением Калмыкии) ответили на этот вопрос положительно.

По-видимому, вал ненормативной лексики в наших городах во многом связан с тем, что более чем $1 / 3$ респондентов эта ненормативная лексика не оскорбляет, а является скорее привычной (за исключением жителей Калмыкии и Адыгеи): 35,9\% из Ростовской обл., 53,3\% - из Волгоградской, более $40 \%$ опрошенных из Крыма, Астраханской обл., Краснодарского края не чувствуют себя оскорбленными, когда слышат ненормативную лексику.

Замечает ли молодежь ненормативную лексику, и как она относится к этому явлению? Анкетный опрос показал, что $83,2 \%$ подростков и $84,4 \%$ молодежи до 30 лет слышат ненормативную лексику. Причем в присутствии респондентов от 31 до 44 лет и старше 60 лет прохожие или употребляют эту лексику немного 
реже, или эти респонденты на нее меньше реагируют (по сравнению с другими возрастными группами), но все равно слышат очень часто (см. табл. 3).

таблица 3

Распределение ответов на вопрос: «Используют ли в Вашем присутствии прохожие ненормативную лексику?», \%

\begin{tabular}{|c|c|c|c|c|c|}
\hline $\begin{array}{c}\text { Варианты } \\
\text { ответа }\end{array}$ & $\begin{array}{c}\text { До 17 лет } \\
\text { включительно }\end{array}$ & $\mathbf{1 8 - 3 0}$ лет & $\mathbf{3 1 - 4 4}$ года & $\mathbf{4 5 - 5 9}$ лет & $\begin{array}{c}\text { 60 лет } \\
\text { и старше }\end{array}$ \\
\hline Да & 83,2 & 84,4 & 81,1 & 85,7 & 77,0 \\
\hline Нет & 16,8 & 15,6 & 18,9 & 14,3 & 23,0 \\
\hline
\end{tabular}

Оскорбляет ли наших горожан ненормативная лексика? Увы, более чем половину самой молодой части опрошенных (57,3\% подростков) ненормативная лексика не оскорбляет (см. табл. 4). Однако сам факт того, что 42,7\% опрошенных подростков и 51,3\% молодых людей до 30 лет чувствуют себя оскорбленными, когда слышат эту лексику, говорит об унижении и бессилии горожан перед теми, кто засоряет аудиальное пространство города. По данным нашего другого социологического исследования «Противоречия и парадоксы социализации студенческой молодежи в условиях транзитивности современного российского общества» 1 , только $34,3 \%$ респондентов считают недопустимым употребление нецензурных выражений и бранных слов, 35,3\% - никогда не употребляют, но и не осуждают, относятся терпимо, 5,8\% используют подобную лексику, чтобы быть «своим», 24,6\% применяют по привычке, не задумываясь, и не видят в этом ничего зазорного для себя и других [Филоненко и др. 2017]. Среди студентов разных типов университетов и курсов обучения зафиксирован рост числа сторонников чистой русской речи и противников ненормативной лексики.

Таблица 4

Распределение ответов на вопрос: «Оскорбляет ли Вас ненормативная лексика?», \%

\begin{tabular}{|c|c|c|c|c|c|}
\hline $\begin{array}{c}\text { Вариант } \\
\text { ответа }\end{array}$ & $\begin{array}{c}\text { До 17 лет } \\
\text { включительно }\end{array}$ & $\mathbf{1 8 - 3 0}$ лет & $\mathbf{3 1 - 4 4}$ года & $\mathbf{4 5 - 5 9}$ лет & $\begin{array}{c}\text { 60 лет } \\
\text { и старше }\end{array}$ \\
\hline Да & 42,7 & 51,3 & 67,3 & 80,3 & 81,0 \\
\hline Нет & 57,3 & 48,7 & 32,7 & 19,7 & 19,0 \\
\hline
\end{tabular}

В традиционной русской культуре ярко выраженный чертой являлась целомудренность, отсутствие показной эротичности. Следует отметить, что, по мнению респондентов, откровенно выражают свою эротичность в поведении или в одежде 43,9\% жителей крупных городов, $25,0 \%$ - средних и $26,6 \%$ горожан из малых городов. Мы видим большую целомудренность у жителей средних городов (по сравнению с малыми), а в целом зависимость от типа города прослеживается от крупнейших до средних городов, что подтверждает гипотезу о большей традиционности культуры жителей средних и малых городов. В данном случае жители малых городов, по мнению респондентов, оказались более смелыми в одежде, но это связано опять же с набором городов этой группы:

\footnotetext{
1 Межрегиональное социологическое исследование осуществлено в рамках внутреннего гранта ЮФУ №ВнГр-07/2017-27 в 2016 г. Общая выборка по 23 вузам/филиалам вузов 9 регионов РФ составила 4387 бакалавров, магистров и аспирантов очной формы обучения.
} 
если $10,0 \%$ респондентов из Адыгейска положительно ответили на данный вопрос, то из Алушты (курортного города) - так же положительно ответили уже $88,2 \%$ респондентов. Стоит обратить внимание и на различие в оценках между жителями крупнейших и крупных городов на 11,2\% (см. табл. 5).

Таблица 5

Распределение ответов на вопрос: «Принято ли в Вашем городе выражать свою эротичность в поведении или в одежде?» (по типам городов), \%

\begin{tabular}{|c|c|c|c|c|c|}
\hline $\begin{array}{c}\text { Варианты } \\
\text { ответов }\end{array}$ & $\begin{array}{c}\text { Крупнейшие города } \\
\text { (более 1 млн жителей) }\end{array}$ & $\begin{array}{c}\text { Крупные } \\
\text { города }\end{array}$ & $\begin{array}{c}\text { Большие } \\
\text { города }\end{array}$ & $\begin{array}{c}\text { Средние } \\
\text { города }\end{array}$ & $\begin{array}{c}\text { Малые } \\
\text { города }\end{array}$ \\
\hline Да & 43,9 & 32,7 & 27,6 & 25,0 & 26,6 \\
\hline Нет & 56,1 & 67,3 & 72,4 & 75,0 & 73,4 \\
\hline
\end{tabular}

Чем опасно такого рода засорение аудиовизуальной среды наших городов? Во-первых, высокой степенью недовольства людьми друг другом. Эту тенденцию можно проследить при ответах на вопрос: «Что бы Вы хотели изменить в вашем городе?». На 1-м месте в крупнейших, крупных и малых городах дается ответ: «сделать город более чистым, уютным» $(46,7 \%, 49,4 \%, 47,7 \%$ соответственно), а на 2-м месте ответ: «изменить людей: сделать их поведение более культурным, уважительным и менее агрессивным» $(45,8 \%, 38,7 \%, 47,7 \%$ соответственно). В больших и средних городах желание изменить людей стоит на 1-м месте: $36,9 \%$ и 45,5\% респондентов выбрали этот вариант ответа из 12 возможных (см. табл. 6).

Второе следствие, представляющее опасность, - желание покинуть страну. О нем можно судить по ответам на вопрос: «Где бы Вы хотели жить?» Большинство респондентов из всех субъектов ЮФО, кроме жителей Астраханской обл., Калмыкии и Адыгеи, хотели бы жить «в крупном городе нашей страны». Однако если для респондентов из Калмыкии и Адыгеи более предпочтительной альтернативой выступает «малый город нашей страны», то для респондентов из Астраханской обл. наиболее предпочтительной представляется жизнь за границей.

О жизни «где-нибудь за рубежом» мечтают также $22,3 \%$ респондентов из Крыма и 33,1\% опрошенных из Волгоградской обл. Обратим внимание также на то, что мнение опрошенных из Краснодарского края разделилось примерно поровну между предпочитаемыми альтернативами жизни в крупном и малом городах.

Таким образом, проведенный сравнительный анализ оценок горожанами отдельных элементов городской среды позволил выявить наличие широкого диапазона социального загрязнения аудиовизуальной среды городов Южного федерального округа - от оскорбительных надписей до ненормативной лексики. Сами горожане оценивают степень этого загрязнения по-разному в зависимости от типа города, возраста респондентов, региональной социокультурной специфики, тем более что очень многое привлекает в южнороссийские города: и климат, и история, и обустройство. Однако остается обширное поле для дальнейшей работы как городских администраций, так и самих жителей. При этом городским менеджерам следует занять более определенную позацию по отношению к явлениям, противоречащим ценностному строю российской культуры, без учета и защиты которого социальная загрязненность будет только усиливаться.

Проведенное исследование открывает перспективу комплексного изучения состояния городской среды, включающей в себя как предметно-веществен- 
таблииа 6

Распределение ответов на вопрос: «Что бы Вы хотели изменить в вашем городе?», \%

\begin{tabular}{|l|c|c|c|c|c|}
\hline & $\begin{array}{c}\text { Крупнейшие } \\
\text { города } \\
\text { (более 1 млн } \\
\text { жителей) }\end{array}$ & $\begin{array}{c}\text { Крупные } \\
\text { города }\end{array}$ & $\begin{array}{c}\text { Большие } \\
\text { города }\end{array}$ & $\begin{array}{c}\text { Средние } \\
\text { города }\end{array}$ & $\begin{array}{c}\text { Малые } \\
\text { города }\end{array}$ \\
\hline $\begin{array}{l}\text { Изменить людей: сделать их } \\
\text { поведение более культурным, } \\
\text { уважительным и менее } \\
\text { агрессивным }\end{array}$ & 45,8 & 38,7 & 36,0 & 45,5 & 32,3 \\
\hline $\begin{array}{l}\text { Сделать город более чистым, } \\
\text { уютным }\end{array}$ & 46,7 & 49,4 & 33,5 & 42,9 & 47,7 \\
\hline Посадить больше деревьев & 24,8 & 17,6 & 19,1 & 18,8 & 18,1 \\
\hline $\begin{array}{l}\text { Наладить работу } \\
\text { общественного транспорта }\end{array}$ & 30,0 & 29,9 & 16,5 & 16,9 & 13,1 \\
\hline Сделать его более безопасным & 21,2 & 18,4 & 15,8 & 11,7 & 16,2 \\
\hline Сделать город более красивым & 26,7 & 32,6 & 34,6 & 38,3 & 46,5 \\
\hline $\begin{array}{l}\text { Уменьшить количество } \\
\text { рекламы }\end{array}$ & 13,4 & 18,0 & 12,9 & 7,8 & 10,0 \\
\hline Уменьшить шум & 18,2 & 14,6 & 9,9 & 8,4 & 4,6 \\
\hline Разбить новые парки и скверы & 13,9 & 21,8 & 25,4 & 22,1 & 30,4 \\
\hline Сделать больше автостоянок & 15,3 & 16,1 & 13,2 & 11,7 & 20,4 \\
\hline $\begin{array}{l}\text { Сделать въезд в центр города } \\
\text { личного автотранспорта } \\
\text { платным }\end{array}$ & 2,8 & 2,3 & 2,6 & 7,1 &, 8 \\
\hline Другое & 2,1 & 3,8 & 9,9 & 12,3 & 3,5 \\
\hline
\end{tabular}

ный, так и социально-культурный срезы. Полученные результаты и исследовательские подходы могут быть положены в основу программ, реализующих Стратегию национальной безопасности Российской Федерации и Стратегию государственной культурной политики на период до 2030 года.

Наш анализ социальной загрязненности аудиовизуальной городской среды не является единственно исчерпывающим анализом. Восприятие и оценки этих процессов людьми, которые населяют город, важны, но прежде всего потому, что через них мы можем судить об утверждающейся культуре, о не проявленных, но уже живущих смыслах, в противовес официально поддерживаемым и провозглашаемым.

Статья выполнена в рамках реализации гранта РФФИ (проект № 18-011-00841 «Развитие аудиовизуальной среды современного российского города в контексте сохранения $и$ трансляции этических иенностей российской культуры»).

\section{Список литературы}

Бодрийяр Ж. 2000. В тени молчаливого большинства, или Конеи социального (пер. с фр. Н.В. Суслова). Екатеринбург: Изд-во Уральского университета. 96 с.

Мертон Р. 1966. Социальная структура и аномия. - Социология преступности (Современные буржуазные теории) (пер. с фр. Е.А. Самарской; ред. пер. М.Н. Грецкий). М.: Прогресс. С. 299-313. 
Микляева А.В., Румянцева П.В. 2011. Городская идентичность жстеля современного мегаполиса: ресурс личностного благополучия или зона повышенного риска? СПб: Речь. 160 с.

Федорова А.Э., Парсюкевич А.М. 2013. Социальное загрязнение от экономической деятельности хозяйствующих субъектов: развитие категориального аппарата. - Управленеи. № 4/44. С. 16-21.

Филоненко В.И., Штомпель Л.А., Штомпель О.М., Магранов А.С. 2017. Культурные установки и стратегии поведения современного российского студенчества (по материалам межрегионального социологического исследования): научная монография (под общ. ред. В.И. Филоненко). Ростов н/Д; Таганрог: Изд-во Южного федерального университета. 304 с.

Felonneau M.L. 2004. Love and Loathing of the City: Urbanophilia and Urbanophobia, Topological Identity and Perceived Incivilities. - Journal of Environmental Psychology. Vol. 24. Is. 1. P. 43-52.

Pfeffer J. 2010. Building Sustainable Organizations: The Human Factor: Research Paper No. 2017. - Academy of Management Perspectives. February.

FILONENKO Viktor Ivanovich, Dr.Sci. (Soc.), Professor; Director of the Center for Socio-political Studies, Institute of Philosophy and Socio-Political Sciences, Southern Federal University (116 Dneprovsky Lane, Rostov-on-Don, Russia, 344065; vfilonenko@sfedu.ru)

SHTOMPEL' Lyudmila Aleksandrovna, Dr.Sci. (Philos.), Professor of the Chair of Cultural Theory, Ethics and Aesthetics, Institute of Philosophy and Socio-political Sciences, Southern Federal University (116 Dneprovsky Lane, Rostov-on-Don, Russia, 344065; lashtompel@gmail.com)

SHTOMPEL' Oleg Mikhaylovich, Dr.Sci. (Philos.), Professor of the Chair of Cultural Theory, Ethics and Aesthetics, Institute of Philosophy and Socio-political Sciences, Southern Federal University (116 Dneprovsky Lane, Rostov-on-Don, Russia,344065; omshtompel@sfedu.ru)

\section{SOCIAL POLLUTION OF THE URBAN ENVIRONMENT AS A FACTOR OF ITS DEGRADATION}

Abstract. The article presents the results of a sociological study of the cities of the Southern Federal District, conducted to determine the degree of social pollution of the audiovisual urban environment. The comparative analysis of the citizens' assessments of certain elements of the urban environment revealed the presence of a wide range of social pollution of the audiovisual environment in the cities of the Southern Federal District: from offensive inscriptions to profanity. A decrease in the value of literary speech and a high level of noise were recorded.

Keywords: social pollution, city, urban environment, audiovisual environment, visual, audial, town dweller 